\title{
Not All Roads Lead to Resilience: a Complex Systems Approach to the Comparative Analysis of Tortoises in Arid Ecosystems
}

\author{
Thomas E. J. Leuteritz $^{1}$ and Hamid R. Ekbia ${ }^{1}$
}

\begin{abstract}
The concept of resilience has been widely used in the study of social-ecological systems, with its key components identified as resistance, latitude, and precariousness. We use this concept to examine the differences among three semi-arid regions in terms of these three components. We do this by examining the status of tortoises that occur in the dry spiny forest Madagascar, the Karoo of South Africa, and the Mojave Desert of the United States as an indicator of the health and resilience of their respective ecosystems. Our findings demonstrate the tight coupling between societal development and ecosystem dynamics, the role of diversity in enhancing resilience, and the significance of local communal knowledge in sustaining it. Our findings also suggest that at each of the three sites, social parameters are the dominant drivers of change in the overall social-ecological system. We borrow the notions of control parameter and collective variable from dynamical systems theory to hypothesize that in present-day societies, social parameters might in fact be the control parameters of the greater social-ecological system, and that resilience is the collective variable that captures and demonstrates the overall behavior of the system.
\end{abstract}

Key Words: collective variable; control parameter; latitude; Madagascar; panarchy; precariousness; resistance; social-ecological systems; South Africa; United States

\section{INTRODUCTION}

The interdependence of social and ecological systems is increasingly recognized among scientists, managers, and policymakers (Folke et al. 2002, Walker et al. 2004). The grave global consequences of positivist science, bureaucratic and control-oriented management styles, and the efficiency-driven policies of the last century drive the recognition of this interdependence, and integrated concepts such as resilience and adaptive management exemplify it. Resilience is a property of a system that provides it with the capacity to absorb shocks while maintaining function. When change occurs, resilience provides the components for renewal and reorganization (Gunderson and Holling 2002, Berkes et al. 2003). The concept of resilience shifts policies from those that aspire to control change in systems that are assumed to be stable to those that manage the capacity of socialecological systems to cope with, adapt to, and shape change. Managing for resilience enhances the likelihood of sustaining development in changing environments in which the future is unpredictable and surprise is likely (Levin 1998, Holling 2001). The flip side of resilience is vulnerability; when a social or ecological system loses resilience, it becomes vulnerable to change that previously could be absorbed (Kasperson and Kasperson 2001). In a vulnerable system, even small changes may be devastating.

Different cultures and societies have developed different ways of dealing with social-ecological change, and a comparative analysis of these attempts reveals interesting contrasts in terms of how social and ecological systems interact, how different cultures respond to environmental feedback, and how, in so doing, they achieve or undermine resilience. We use the concept of resilience to compare the status of tortoises in arid habitats. Many tortoise species are recognized as endangered in different areas of the globe (Klemens 2000). Here, we consider three major habitat areas of arid-land tortoises: Madagascar, South Africa, and the United States. We observed three different socio-cultural contexts with their unique combinations of attitudes, resources, knowledge pools, policies, 
and management practices toward these species. These differing local contexts have given rise to social-ecological systems with different stability landscapes. An analysis of these landscapes in terms of resilience will reveal the interactions between societal development and ecosystem dynamics, the role of diversity in enhancing resilience, and the significance of local communal knowledge in sustaining resilience. It will also reveal the dominant drivers of change in the overall social-ecological systems. In short, a comparative analysis of the kind conducted here can shed some light on these issues in a way that is not achievable in single-site studies.

We use the framework proposed by Walker et al. (2004) to articulate and show the differences among these landscapes in terms of latitude, resistance, and precariousness. We borrow the notions of "control parameter" and "collective variable" from dynamical systems theory to formulate this observation, i.e., to hypothesize that in present-day societies, social parameters might in fact be the control parameters of the greater social-ecological system and that resilience is the collective variable that captures and demonstrates the overall behavior of the system. This formulation might provide useful insights into how resilience can be "engineered" (Holling 1996) and how different stability landscapes can emerge in different contexts. We discuss the implications of these results for ecosystem management and policy.

\section{Resilience as a collective variable}

The concept of resilience has been widely used in the study of complex adaptive systems such as social-ecological systems (Holling 1986, 2001). There are, however, different characterizations and understandings of this concept among various groups. The Resilience Alliance (http://www.resall iance.org), for example, provides three characteristic features of resilient systems that have to do with their capacity to absorb disturbance, their capability to reorganize, and the capacity for learning and adaptation. Although these might be related features, it is not clear if they always align with each other, i.e., if having one would necessarily bring about the other. This kind of conceptual ambiguity might be inherent to a notion such as resilience, but it also suggests the need for more rigorous frameworks. Walker et al. (2004) have addressed this issue by applying the theory of nonlinear stability to a number of known examples of regional development and sustainability. We use a similar approach.

According to Walker et al. (2004), resilience, which is thought of as a property of a stability landscape, has four critical aspects: (1) latitude: the maximum that a system can be changed before it loses its ability to recover; (2) resistance: the ease or difficulty of changing the system; (3) precariousness: the closeness of the current system to a limit or threshold; and (4) panarchy: a system's dependence at a particular focal scale on the influences of states at scales above and below (Fig. 1). However, we focus on the first three dimensions here and exclude panarchy from our analysis because panarchy relates to higher-level scale effects. We will come back to this concept in discussing uncertainties of global climate change at the end of the paper.

It is difficult, if not impossible, to come up with quantitative and formal representations of the stability landscape for complex social-ecological systems. However, as Walker et al. (2004) point out, the general concepts still apply. Although qualitative in nature, an overall assessment of the four aspects of resilience can provide the analyst with a relatively accurate picture of the current state of the system and its possible future behavior. Equally important, however, is to have a similar qualitative understanding of how a stability landscape develops through the interaction of different system components. We seek to arrive at such an understanding by introducing the notions of control parameter and collective variable from dynamical systems theory (Kelso 1995). To illustrate these concepts, we introduce the example of the overarching fluctuations in the Canadian lynx (Lynx canadensis) fur trade data collected over two centuries by the Hudson Bay Company (Schaffer 1984, Gamarra and Solé 2000). The predator-prey dynamics of the lynx and hare produced a 10-yr cycle in lynx returns. In 1820 and again in 1910, there was a significant shift in the amplitude of oscillations in the lynx time series. These abrupt shifts can be attributed to changes in trapping pressure from either amalgamation of competing trapping companies or price change. Changes in the amplitude of oscillation gave rise to two different phases. These phases in turn can be said to represent a shift between two different basins of attraction in lynx population dynamics (Gamarra and Solé 2000). 
Fig. 1. Three-dimensional stability landscape with two basins of attraction showing the current position of the system (red dot) and three aspects of resilience: $\mathrm{L}=$ latitude, $\mathrm{R}=$ resistance, $\mathrm{Pr}=$ precariousness (adapted from Walker et al. 2004).

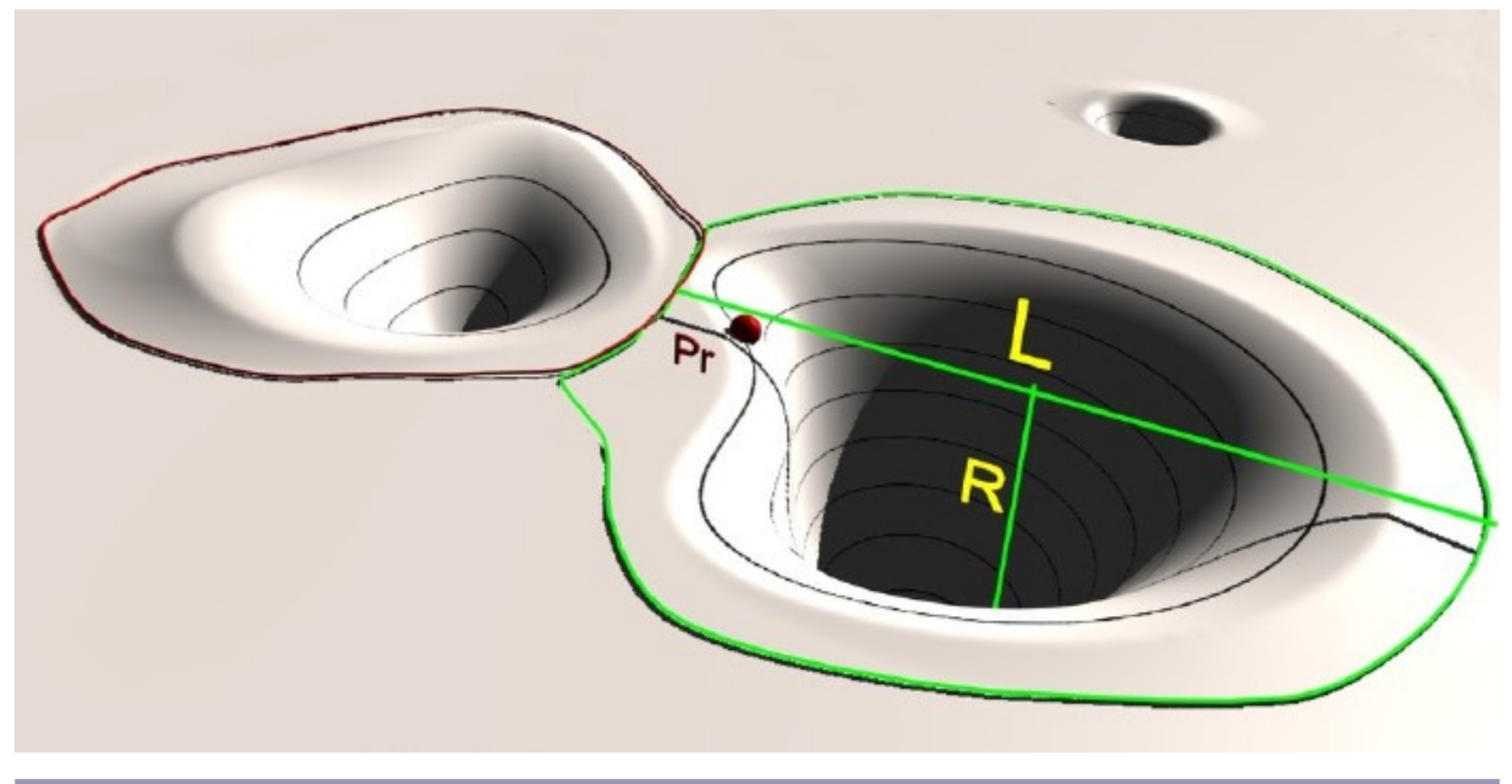

As this example illustrates, the outstanding feature of the fluctuations in lynx populations is the emergence of a particular behavior, i.e., the amplitude of oscillation, caused by the tweaking of a particular parameter, namely harvest pressure. This is an example of a self-organized system of which the behavior can be best explained not in terms of a single cause, but in terms of interactions among components as they are driven by changing the control parameter. The metaphor here is one of tweaking a parameter to obtain certain outcomes (Hofstadter 1979). We use a similar idea to explain the development of stability landscapes in socialecological systems; that is, the idea that in such systems, human activity, broadly understood, is the control parameter that generates patterns of behavior and the stability landscape and that resilience is the collective variable that emerges from the tweaking of the control parameter. We understand human activity in very broad terms, including but not limited to daily life, leisure, hunting, transportation, construction, and so on.

\section{METHODOLOGY}

This study is based on field observations and data collected for ecological studies of three species of tortoise over $5 \mathrm{yr}$ by Leuteritz and colleagues (Leuteritz 2002, Leuteritz and Ravolanaivo 2005, Leuteritz et al. 2005, Leuteritz 2006, Leuteritz and Hofmeyr 2007). The focus of the field observations was tortoise demography, reproduction, nutrition, and movement, as well as climatic influences and threats to the tortoises, e.g., predation, harvesting, and other human influences. As we explain later, we use this data, especially population size and degree of threat, as an indicator of the third dimension of ecosystem resilience, namely, precariousness.

We also examined the social-ecological interactions of tortoises and people in the three regions, two of which are located in Africa and one in North America. Participant observations were made while living in these regions for a total of $5 \mathrm{yr}$ : $1 \mathrm{yr}$ in Madagascar, $2 \mathrm{yr}$ in South Africa, and $2 \mathrm{yr}$ in the 
United States. Anecdotal information on tortoises and human interactions was gathered by talking with local people and land managers. In the U.S. case, part of the information gathered came through community outreach and stakeholder involvement. This information is used here to discuss the feedback mechanisms that developed historically in the three regions and how they contribute to the second dimension of resilience, namely, resistance.

Lastly, we reviewed other ecological studies of the three regions to gain insight into their similarities and differences in terms of their ecological features (Dean and Milton 1999, Myers et al. 2000, Whitford 2002, Goodman and Benstead 2003, Hooper et al. 2005; see also Conservation International biodiversity hotspots http://www.biodiversityhotspots. org/xp/Hotspots and World Wildlife Fund, biomes and biogeographical realms http://worldwildlife.org/ science/ecoregions/biomes.cfm2006). Of particular interest among these ecological features was biodiversity, which we tie to the first dimension of resilience, namely, latitude. In addition, secondary data on socioeconomic indicators of the three regions were obtained from The World Factbook (Central Intelligence Agency 2006) to compare the regions along this dimension.

\section{Study sites and species}

Madagascar's radiated tortoise (Geochelone radiata) is the largest (up to $40 \mathrm{~cm}$ long) of the three species discussed here. It is a striking tortoise that has a black shell with yellow lines radiating from the centers of the individual scutes (plates on the shell). It occurs in the arid southwest of Madagascar in a habitat known as spiny dry forest (Fig. 2A). This region is occupied by two groups of native peoples: the Antandroy and the Mahafaly (Leuteritz et al. 2005).

South Africa has the highest diversity of tortoises in the world: one-third of all tortoise species. We consider two very closely related species here: geometric tortoise (Psammobates geometricus) and tent tortoise (Psammobates tentorius). Both tortoises are small (up to $15 \mathrm{~cm}$ long) and have a dark brown shell with yellow or orange lines radiating from the centers of the scutes. Geometric tortoise is found in renosterveld (rhinoceros bush) habitat, located $50 \mathrm{~km}$ northeast of Cape Town, in what is considered a Mediterranean climate zone. Its more arid-adapted cousin, tent tortoise, is found
$400 \mathrm{~km}$ east of Cape Town in the Karoo (Boycott and Bourquin 2000; Fig. 2B).

The last species that we consider is the North American desert tortoise (Gopherus agassizii). It is a medium-sized (20-38 cm long) burrowing tortoise that has a brown shell. It is found in the Mojave and Sonoran deserts of the southwestern United States and northern Mexico (Ernst et al. 1994; Fig. 2C). Its range is flanked by several large urban areas: to the west by Los Angeles, to the east by Phoenix, and to the north by Las Vegas.

\section{FINDINGS}

\section{Tortoise population threats and status}

Tortoises face three common threats that are responsible for the decline of many chelonian species worldwide: harvesting/exploitation for food, medicines, or the pet trade; habitat loss and degradation; and the introduction of disease. All three regions considered here are affected by some or all of these problems, but with different outcomes to the individual species under examination. The status of tortoises, obtained by examining the population size and degree of threat, can be used to reflect ecosystem health.

\section{Madagascar}

In Madagascar, tortoises are collected for two purposes: the international pet trade and local people or people in other parts of Madagascar. Illegal international trade of radiated tortoise has made the news in recent years, with the smuggling of tortoises by Dutch, German, and Japanese nationals (Webster 1997; C. Hoover, World Wildlife Fund Office of Traffic personal communication). Within Madagascar, the Mahafaly and Antandroy, whose land covers the majority of the range of the radiated tortoise, do not use the tortoise. They have a taboo ( $\mathrm{fady}$ ) against eating or touching tortoises (Leuteritz 2002, Lingard et al. 2003, Leuteritz et al. 2005). However, large numbers of radiated tortoise are gathered by recent immigrants to the region or by people who are traversing the tortoise's range. There have been incidences of truck- or ox-cart-loads of tortoises being taken back to larger cities such as Tuléar or Antananarivo, where tortoise meat is especially popular around Christmastime (Nussbaum and Raxworthy 2000). In addition to being used as food, 
Fig. 2. Photographs of the tortoises (insets) and tortoise habitat of the three study regions. (A) Radiated tortoise, dry spiny forest at Cap Sainte Marie, Madagascar. (B) Tent tortoise, Karoo near Prince Albert, South Africa. (C) Desert tortoise, Mojave Desert, California, USA. Photos: T. E. J. Leuteritz.

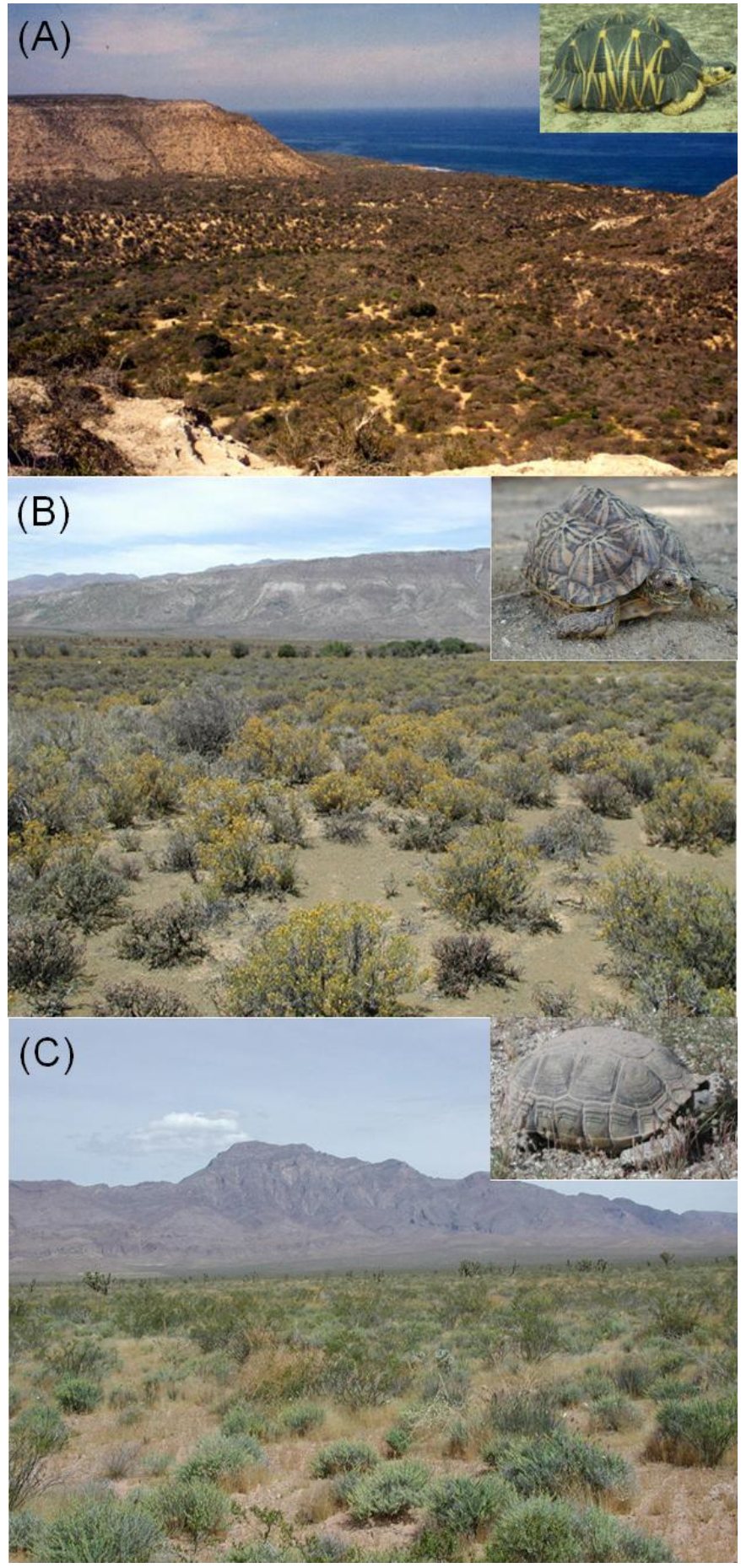


the Malagasy keep tortoises for good luck, as well as in pens with chickens and ducks as a means to ward off poultry diseases (Durrell et al. 1989, Leuteritz 2002).

Although tortoise habitat loss does occur because of slash and burn clearing (tavy), overgrazing of livestock, and charcoal production (Nussbaum and Raxworthy 2000), it is not as severe as that in South Africa and the United States, where large urban populations put pressure on tortoise habitat. Radiated tortoise population numbers are still high in Madagascar (Leuteritz et al. 2005).

\section{South Africa}

Traditionally tortoises in South Africa have been used as a food source by indigenous peoples and cooked in the shell (for a description see Michener 1980). Although this may still occur in limited instances, it is not a major source of tortoise mortality (T. E. J. Leuteritz personal observation). The fundamental threat to the geometric tortoise comes from the loss of its renosterveld habitat because of agricultural development. Renosterveld has a very limited distribution, and up to $97 \%$ has been converted to wheatlands, vineyards, orchards, and grazing land (Baard 1997). Geometric tortoise habitat is highly fragmented, and only small isolated populations that are tightly clustered remain, making this species very vulnerable to extinction. The more arid-adapted tent tortoise, a very close relative of geometric tortoise, is more broadly distributed in South Africa and into Namibia, but we know very little about its historic or present population numbers or how they have changed over time (Leuteritz and Hofmeyr 2007).

\section{United States}

The indigenous peoples of the Sonoran Desert such as the O'odham and Comcàac traditionally used tortoises or their eggs as a food source, for jewelry boxes and musical instruments, and for medical purposes. However, these traditions have almost died out with the rapid cultural and dietary changes of the 20th century. These changes have brought the "extinction of experience" and the decline of informal stewardship for this species (Nabhan 2002). The O'odham people saw the tortoise as the keeper and planter of the giant saguaro cactus, which in their culture is a key resource of the region. Nabhan (2002) points out that although the O'odham and Comcàac may have hunted and even in some cases exploited the tortoise, they nonetheless had cultural taboos in place, many of which were transmitted from generation to generation by songs or poems; these regulated who, when, where, and how people could use the tortoise.

Desert tortoise populations have been declining throughout their historic range because of humanrelated threats, including habitat loss, destruction, and fragmentation; localized extinctions; increased numbers of subsidized predators such as ravens and coyotes; road kills; spread of disease; illegal collecting; feral dogs; and military activity (W. Boarman unpublished report). Because of the complexity of these threats, examining their synergistic interactions is viewed as a more comprehensive way to understand threats to desert tortoise (Tracy et al. 2004). The assessment of actual population numbers has been problematic despite intensive effort and large sums of money invested into line distance sampling methodologies (T. E. J. Leuteritz personal observation).

\section{Ecological comparison}

The three main regions under study here represent three different social-ecological systems. Ecologically, however, these three regions have similarities (Dean and Milton 1999, Whitford 2002, Goodman and Benstead 2003). Madagascar's dry spiny forest covers an area of $44,300 \mathrm{~km}^{2}$ and represents $7.5 \%$ of the country's total area. South Africa's succulent Karoo covers an area of 102,691 km² and represents $8.6 \%$ of the total area. Finally, the United States' Mojave Desert covers an area of $130,600 \mathrm{~km}^{2}$ and represents $1.4 \%$ of the total area. Dry spiny forest is dominated by Didiereaceae and Euphorbia. The rainy season occurs from October to April, but is often erratic. The south has the highest percentage of Madagascar's plant endemism and therefore contains a significant proportion of the 11,600 endemic plants found on the island. The Karoo is mostly winter rainfall desert with dwarf shrubland dominated by leafy succulents. There are approximately 2439 endemic plant species found in the Karoo (Conservation International, biodiversity hotspots http://www.biodiversityhotspots.org/xp/ Hotspots; World Wildlife Fund, biomes and biogeographical realms http://worldwildlife.org/sci ence/ecoregions/biomes.cfm2006). The Mojave is a winter rainfall desert dominated by creosote bush, bursages, and all-scale, with Yucca occurring at higher elevations and cactus in the coarser soils of 
the bajadas, which are broad, sloping depositional deposits caused by the coalescing of alluvial fans. Approximately 200 endemic plants are found here (World Wildlife Fund, biomes and biogeographical realms http://worldwildlife.org/science/ecoregions/ biomes.cfm2006).

The three regions are all arid areas located in the southwestern portion of their respective countries and receive $<300 \mathrm{~mm}$ of rainfall per year. Compared to nonarid areas, they have relatively low species diversity, so any loss is proportionally higher. Soil fragility, i.e., the ability of soils to bind, absorb water, retain microorganisms under harsh conditions, and retain nutrients, is problematic. These areas are often heavily grazed by domestic livestock. Because the organisms that occur in arid ecosystems are highly adapted to extremes, they are also susceptible to climate change. However, there are differences in biodiversity among the regions. The arid regions of Madagascar and South Africa have higher biodiversity than does that of the United States, and they have very high vertebrate and especially plant endemism (Myers et al. 2000).

\section{Socioeconomic comparison}

Given the similarities of the ecosystems, the differences among the three regions are mainly socioeconomical (Table 1). We have observed three different socio-cultural contexts with their unique combinations of cultures (e.g., taboos), resources, knowledge practices, laws, policies, and management practices toward tortoise species.

\section{Madagascar}

Madagascar has a largely agricultural economy, with $80 \%$ of the population employed in fishing, forestry, and related industries. The use of firewood as a primary source of fuel has lead to deforestation and erosion (Central Intelligence Agency 2006). Nationally, Malagasy law (Decree 60126 of October 1960) protects radiated tortoise via fines and imprisonment (Groombridge and Wright 1982, Durrell et al. 1989). However, enforcement is difficult, and the corruption of local law enforcement officials leads to the continued collection of tortoises (Webster 1997). Internationally, the radiated tortoise was listed in Category A of the African Conservation Convention of 1968; since 1975, it has been listed in Appendix I of the Convention on International Trade in Endangered
Species of Wild Fauna and Flora (CITES), which affords species the highest level of protection. CITES regulates international trade, including that for commercial purposes (Groombridge and Wright 1982, Durrell et al. 1989).

It is our contention that the adherence to the fady is largely responsible for the large numbers of this species of tortoise still in existence today. In essence, the fady serves as a regional law. Furthermore, the respect for, reinforcement of, and adherence to the fady can serve as a means of conservation and sustainable management of this species (Leuteritz 2002, Lingard et al. 2003, Leuteritz et al. 2005).

\section{South Africa}

South Africa is an emerging middle-income market economy with an abundant supply of natural resources and well-developed infrastructure. This has lead to the development of laws that regulate the use of resources and the environment (Central Intelligence Agency 2006). South Africa established the National Environmental Management Act in 1998 for the protection of species and ecosystems, and most recently, adopted the Biodiversity Act (October 2004), which has the objectives of managing and conserving biodiversity in a sustainable manner with benefits to all stakeholders, authorizing international biodiversity agreements, and establishing a South African National Biodiversity Institute to oversee these types of issues. At the provincial level, the geometric tortoise is listed under Schedule 1 in the Western Cape Nature Conservation Laws Amendment Act of 2000 as endangered wildlife. All other tortoises are listed under Schedule 2 as protected wildlife. Internationally, the geometric tortoise is listed in Appendix I of CITES, which affords species the highest level of protection in international trade.

\section{United States}

The United States has a technologically advanced and a strongly market-oriented economy and a largely unregulated business environment in which private firms enjoy considerable autonomy in the use of the abundant natural resources (Central Intelligence Agency 2006). The ecological implications of this unregulated environment are that it leads to the decline of certain species; these declines resulted in a call for some kind of legislative 
Table 1. Socioeconomic comparison of the three regions (Central Intelligence Agency 2006).

\begin{tabular}{lccc}
\hline \hline Variable & Madagascar & South Africa & United States \\
\hline $\begin{array}{l}\text { Population/labor force } \\
\text { (million) }\end{array}$ & $18.0 / 7.3$ & $44.3 / 16.6$ & $295.7 / 147.4$ \\
GDP (\$ billion) & 14.56 & 491.4 & $11,705,000$ \\
$\begin{array}{l}\text { Purchasing power (\$, 2004 } \\
\text { estimate) }\end{array}$ & 800 & 11,100 & 40,100 \\
$\begin{array}{l}\text { Population below poverty line } \\
(\%)\end{array}$ & 50 & 50 & 12 \\
$\begin{array}{l}\text { Population growth rate (\%) } \\
\text { Life expectancy at birth (yr) }\end{array}$ & 3.03 & -0.3 & 0.92 \\
$\begin{array}{l}\text { HIV/AIDS adult prevalence } \\
\text { rate (\%) }\end{array}$ & 1.7 & 43.27 & 77.71 \\
Sex ratio (male:female) & $0.99: 1$ & 21.5 & 0.6 \\
Literacy rate (\%) & 68.9 & $0.94: 1$ & $0.97: 1$ \\
& & 86.4 & 97 \\
\hline
\end{tabular}

intervention for species' protection. In 1973, the U. S. Congress established the Endangered Species Act "to provide a means whereby the ecosystems upon which endangered species and threatened species depend may be conserved, to provide a program for the conservation of such endangered species and threatened species, and to take such steps as may be appropriate to achieve the purposes of the treaties and conventions set forth." This act is administered through the U.S. Fish and Wildlife Service.

In 1980, the desert tortoise population at Beaver Dam Slope, Utah, was federally listed as threatened. In 1989, there was an emergency listing of all desert tortoise populations north and west of the Colorado River (i.e., the Mojave population) as endangered. In 1990, the entire Mojave population was subsequently re-listed as threatened (Fish and Wildlife Service 1994). The desert tortoise is distributed throughout four states, i.e., California, Nevada, Utah, and Arizona, and therefore has both federal and state protection. All of the states require permits for the collection or possession of state- listed protected wildlife. In California and Nevada, the tortoise is listed as threatened under the California Endangered Species Act and the Nevada Administrative Code, respectively. Utah and Arizona do not have individual state species legislation. In Utah, the Department of Natural Resources classifies wildlife into three categories; the desert tortoise is classified as prohibited and thus requires a Certificate of Registration for possession. In Arizona, the tortoise is on the state's list of Threatened Native Wildlife and is therefore protected by Orders 41 and 43 of the Arizona Game and Fish Commission (Levell 1995). Internationally, the desert tortoise is listed in Appendix II of CITES, which requires permits for collection or scientific use in international trade.

\section{DISCUSSION}

Our findings reveal interesting similarities and differences among the three regions examined here. As major habitats of arid-land tortoises, these 
regions manifest similar ecological features in terms of rainfall, species diversity, soil fragility, and climate change. This suggests that they might also be similar in terms of their stability/resilience and its three constitutive aspects, namely, latitude, resistance, and precariousness. However, as we discuss below, there are stark dissimilarities among these regions (Fig. 3).

Latitude provides a measure of the room for disturbance to the ecosystem. The presence of high biodiversity makes it possible for the replacement of lost species if and when disturbances occur, providing more latitude for maneuvering in the overall system (Pimm 1984, McCann 2000, Tilman 2000, Hooper et al. 2005). As described earlier, Madagascar and South Africa are similar with regard to biodiversity, but the United States ranks much lower in this regard. Given the correlation between latitude and biodiversity, this gives the first two regions a considerable degree of latitude, whereas in the situation of the Mojave Desert, which has less biodiversity, there is less latitude. It might be argued that the effect of biodiversity would be reduced in regions that have high endemism such as Madagascar. It is true that high endemism may lead to high niche specificity, but on the other hand, a larger number of species also increases the probability of finding species to fill the void.

Resistance, in contrast, has mostly to do with the kinds of negative feedback mechanisms that a system has developed in the course of its history. For example, the human body, despite its precariousness, is a highly resistant system because of the evolution of feedback mechanisms such as temperature regulation (Walker et al. 2004). Therefore, if we only consider the natural evolution of the three regions, they should be comparable because they have all developed ecological feedback mechanisms during their millions of years of history. However, if we consider human interventions with regard to feedback mechanisms, the scale is tipped. These mechanisms have various manifestations in the three regions: in the United States, they are mostly embodied in modern ecosystem management practices; in Madagascar, they are mainly the product of traditional cultural practices such as taboos against eating tortoises; in South Africa, they are a mixture of the two. This might suggest that the three regions are also comparable in terms of human-driven feedback, each one having implemented its own mechanisms in dealing with the ecosystem. However, given that modern managerial practices are very recent, they are not yet fully ingrained as feedback mechanisms in the social-ecological system. Thus, even if we assume that these practices have been effective, an assumption that is generous on different accounts (Norton 1992, Abel and Stepp 2003), their short history might make their effects much less significant than the alternative traditional cultural practices. In other words, despite systematic managerial interventions in a modern society, it is difficult to discern any significant advantage over traditional societies in this respect. Although, historically speaking, Madagascar has a shorter history of human presence (almost $2000 \mathrm{yr}$ ) compared to the other two regions, we are comparing these $2000 \mathrm{yr}$ to the $<100 \mathrm{yr}$ of modern ecosystem management practices. Overall, given the uncertainties involved and for the sake of our argument, we can assume that the three regions are comparable in terms of resistance, that is, in terms of how difficult it is to change them.

What parameters in the social-ecological system contribute to precariousness? It is indeed difficult to provide a general answer to this question. However, if we take the status of tortoises in these three regions as an indicator of the quality of the ecosystem, as we earlier suggested, then we might find useful clues to the answer. Briefly, the status of the tortoise is reflected in its population size and in the degree of threat to which it is exposed. In terms of populations of our target species, Madagascar has the largest population of tortoises relative to area, with South Africa and the United States ranking second and third, respectively. Our observations in the three regions suggest that the threat is highest in the United States and Madagascar, and lowest in South Africa. We attribute this to what we earlier called human activity. In the Mojave Desert, the most serious threat to the species comes from extensive development, road construction, and military activity. In Madagascar's dry spiny forest, the most serious threat derives from harvesting and habitat loss through farming and grazing. In the Karoo, there is habitat loss through both agriculture and development, but these activities are relatively contained and localized, making the overall threat much less severe. These observations suggest that the situation in the United States is most precarious, followed by Madagascar and then South Africa.

To summarize this discussion of the three components of resilience, the arid region in the 
Fig. 3. Stability landscapes representing arid ecosystems in (A) the United States, (B) South Africa, and (C) Madagascar. There are differences in the lower basin of attraction in terms of the precariousness of the current position of the system (location of the red dot) and basin's latitude. Resistance is the same in all three basins.

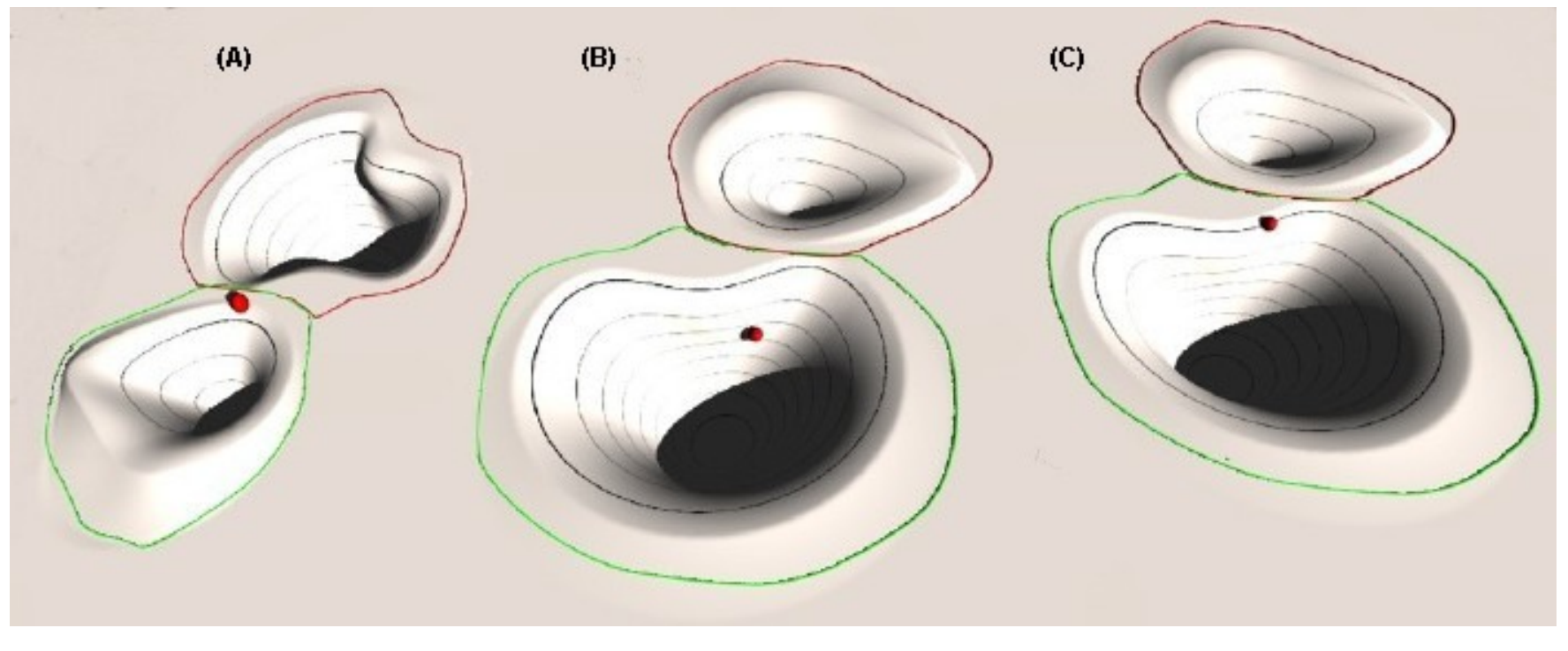

United States is the least resilient ecosystem, whereas that in South Africa is the most resilient, and Madagascar's arid region falls somewhere in between the two (Table 2). Table 2 also demonstrates our earlier point about the role of human activity as the control parameter in the overall dynamic social-ecological system. Assuming, that the three regions are comparable in terms of resistance, they are differentiated in terms of latitude by biodiversity and in terms of precariousness by human activity. In particular, given the comparable levels of biodiversity between Madagascar and South Africa, the role of human activity becomes prominent in tipping the balance for tortoise status.

\section{CONCLUSION}

Our goal was to apply the notion of resilience to understand and study the interactions between the social and ecological aspects of the environment. Our study across three regions indicates that social, economic, and cultural aspects play significant roles in the evolution of the overall system to the extent that one could consider these aspects the control parameters that drive the progression of the socialecological system. In the three regions examined, we discovered noticeable differences in their quality as habitats for the tortoises, mostly on the basis of socioeconomic differences.

The comparison of these regions in terms of the three dimensions of resilience allowed us to tease apart the different aspects of the social-ecological system and discover particular mechanisms that seem to contribute to each dimension, e.g., biodiversity, feedback mechanisms, management practices, cultural traditions, and the history of human activity. More importantly, it led us to the conclusion that modern management practices are not necessarily the best way to achieve resilience. Although it might be too early to make final judgments about the efficacy of such practices, we can safely claim that traditional belief systems, cultural practices, and local knowledge of communities are no less effective than modern scientific knowledge and management practices (Folke et al. 2002).

However, we must qualify these conclusions by accounting for the uncertainties involved in the possible future trajectories of the three regions. Such 
Table 2. Evaluation of resilience and its components in a comparison of the status of tortoises from three arid regions.

\begin{tabular}{lccc}
\hline \hline Variable & $\begin{array}{c}\text { Dry spiny forest, } \\
\text { Madagascar }\end{array}$ & $\begin{array}{c}\text { Karoo, } \\
\text { South Africa }\end{array}$ & $\begin{array}{c}\text { Mojave Desert, } \\
\text { United States }\end{array}$ \\
\hline Latitude & high & high & low \\
Resistance $\dagger$ & - & - & - \\
Precariousness & medium & low & high \\
Resilience & medium & high & low \\
& & & \\
\hline
\end{tabular}

Note: High latitude and high resistance are favorable, whereas high precariousness is not.

$\dagger$ We assumed that the resistance of the three regions is comparable.

uncertainties can derive from either ecological or socioeconomic changes. We consider both sources of uncertainty here. In terms of ecological uncertainty, the most relevant ecological change would be one of climate change resulting from global effects. As Kinzig et al. (2006) demonstrated in their study of southern Madagascar, severe drought might lead to extensive out-migration and hence to either the slow regeneration of forest because of the reduced human presence or rapid deforestation because of the collapse of local rights and immigration of outsiders. In South Africa, studies of climate change predict a southeastward movement of the ecological regions (e.g., desert, grassland, fynbos), which would considerably reduce tortoise habitat within the next few decades (Midgley et al. 2001, Thomas et al. 2004). In the Mojave Desert, elevated $\mathrm{CO}_{2}$ levels would stimulate the growth of invasive grasses that alter the fire regime, and both would ultimately reduce biodiversity in the region (Smith et al. 2000). In brief, all three regions will be affected by climate change in ways that reduce tortoise habitat, albeit in different manners. The driving force in all three regions, however, is still human activity, but on a global scale. This observation reinforces our claim about the central role of human activity in driving resilience, but because of the global character of this effect, it might seem that not much can be done on the regional scale. This is not so! The interaction among scales is captured in the notion of panarchy, which we excluded from the analysis. It can now be seen how this notion relates to a discussion of resilience. Increasing stability at the regional level (spiny forest, Karoo, and Mojave Desert) mitigates the effect of high-level scales (i.e., global) on the individual system. A land manager might not be able to do much in terms of global climate change, but she/he can decrease the effect of the change on the region by enhancing regional resilience. In the language introduced at the outset, the manager can tweak manageable parameters at the local level to attain greater stability. This outlook applies even at smaller scales. As Walker et al. (2004: Introduction, Transformability) observed, "All else being equal, a system that loses resilience at small, and more societally manageable, scales of organization (e.g., patches) will be more resilient than one where these losses occur at larger scales (e.g., landscapes)."

This brings us to the second source of uncertainty, namely, socioeconomic change. In this case also, uncertainties in the three regions derive from various activities, practices, and institutions. In Madagascar, the reinforcement of local institutions can lead to the protection and restoration of habitat (Kinzig et al. 2006); in South Africa, changes in agricultural practices are the determining force 
affecting the habitat (Baard 1997); and in the United States, changes in land management practices can lead to varying outcomes. Therefore, the future trajectories of these regions depend on how the local populations, government agencies, and nongovernmental organizations deal with the current developments. In Madagascar, for instance, Kinzig et al. (2006) argue that the grassroots engagement of the local population provides the most promising path in restoring habitats. The same might not be the case in the other two regions. In the Mojave Desert, for example, the most effective trajectory seems to be adherence to the existing legislation and the maintenance of a continuous dialogue among various stakeholders such as private landowners, off-highway vehicle users, the military, and other land management agencies (Leuteritz 2006).

Similar arguments can be made about tortoise conservation. One of the key lessons here is that each society has to build on its own social, cultural, and institutional strengths to deal with issues of conservation and habitat restoration. Indeed, if our analysis is correct, Madagascar, where local traditions impose certain constraints and taboos with regard to tortoises, offers a more resilient system than the United States, where modern management practices have been in effect for the last few decades (Abel and Stepp 2003). In other words, it is not how rich a society is and how many resources it allocates to conservation initiatives that guarantee ecosystem resilience. It is how the society organizes human activity and intervention in the environment that determines its future trajectory: Not all roads lead to resilience.

Responses to this article can be read online at:

http://www.ecologyandsociety.org/voll3/iss1/art1/responses/

\section{Acknowledgments:}

We thank the Redlands Institute for its continuing support and for providing the right setting for the development of the ideas presented here. Thanks to Tony Turner for the creation of the threedimensional stability landscape figures.

\section{LITERATURE CITED}

Abel, T., and J. R. Stepp. 2003. A new ecosystems ecology for anthropology. Conservation Ecology 7 (3): 12. [online] URL: http://www.consecol.org/vol7/ iss $3 / \operatorname{art} 12$.

Baard, E. H. W. 1997. A conservation strategy for the geometric tortoise, Psammobates geometricus. Pages 324-329 in J. Van Abbema, editor. Proceedings: conservation, restoration, and management of tortoises and turtles-an international conference (July 1993, State University ofNew York, Purchase). New York Turtle and Tortoise Society, New York, New York, USA.

Berkes, F., J. Colding, and C. Folke, editors. 2003. Navigating social-ecological systems: building resilience for complexity and change. Cambridge University Press, Cambridge, UK.

Boycott, R. C., and O. Bourquin. 2000. The South African tortoise book: a guide to South African tortoises, terrapins, and turtles. Revised edition. $\mathrm{O}$. Borquin Publishers, Hilton, South Africa.

Central Intelligence Agency. 2006. The world factbook. Central Intelligence Agency, Washington, D.C., USA. [online] URL: http://www.cia.gov/cia/ publications/factbook/index.html.

Dean, W. R. J., and S. J. Milton, editors. 1999. The Karoo: ecological patterns and processes. Cambridge University Press, Cambridge, UK.

Durrell, L., B. Groombridge, S. Tonge, and Q. Bloxam. 1989. Geochelone radiata: radiated tortoise, sokake. Pages 96-98 in I. R. Swingland and M. W. Klemens, editors. The conservation biology of tortoises. Occasional Papers of the IUCN Species Survival Commission, number 5. IUCN, Gland, Switzerland.

Ernst, C. H., R. W. Barbour, and J. E. Lovich. 1994. Turtles of the United States and Canada. Smithsonian Institution Press, Washington, D.C., USA.

Fish and Wildlife Service. 1994. Desert tortoise (Mojave population) recovery plan. Unpublished report to the U.S. Fish and Wildlife Service, Portland, Oregon, USA. Available online at: http:// ecos.fws.gov/docs/recovery plans/1994/940628.pdf 
Folke, C., S. Carpenter, T. Elmqvist, L. Gunderson, C. S. Holling, B. Walker, J. Bengtsson, F. Berkes, J. Colding, K. Danell, M. Falkenmark, L. Gordon, R. Kasperson, N. Kautsky, A. Kinzig, S. Levin, K.-G. Mäler, F. Moberg, L. Ohlsson, P. Olsson, E. Ostrom, W. Reid, J. Rockström, H. Savenije, and U. Svedin. 2002. Resilience and sustainable development: building adaptive capacity in a world of transformations. Scientific background paper on resilience for the process of The World Summit on Sustainable Development on behalf of The Environmental Advisory Council to the Swedish Government. Environmental Advisory Council, Ministry of the Environment, Stockholm, Sweden. Available online at: http://www.sou.gov.se/mvb/pdf/ resiliens.pdf.

Gamarra, J. G. P., and R. V. Solé. 2000. Bifurcations and chaos in ecology: lynx returns revisited. Ecology Letters 3(2):114-121.

Goodman S. M., and J. P. Benstead, editors. 2003. The natural history of Madagascar. University of Chicago Press, Chicago, Illinois, USA.

Groombridge, B., and L. Wright, editors. 1982. The IUCN Amphibia-Reptilia red data book: part 1 Testudines, Crocodylia, Rhynchocephalia. IUCN, Gland, Switzerland.

Gunderson, L. H., and C. S. Holling, editors. 2002. Panarchy: understanding transformations in human and natural systems. Island Press, Washington, D.C., USA.

Hofstadter, D. R. 1979. Gödel, Escher, Bach: an eternal golden braid. Basic Books, New York, New York, USA.

Holling, C. S. 1986. The resilience of terrestrial ecosystems: local surprise and global change. Pages 292-317 in W. C. Clark and R. E. Munn, editors. Sustainable development of the biosphere. Cambridge University Press, Cambridge, UK.

Holling, C. S. 1996. Engineering resilience versus ecological resilience. Pages 31-44 in P. C. Schulze, editor. Engineering within ecological constraints. National Academy Press, Washington, D.C., USA.

Holling, C. S. 2001. Understanding the complexity of economic, ecological, and social systems. Ecosystems 4(5):390-405.
Hooper, D. U., F. S. Chapin III, J. J. Ewel, A. Hector, P. Inchausti, S. Lavorel, J. H. Lawton, D. M. Lodge, M. Loreau, S. Naeem, B. Schmid, H. Setälä, A. J. Symstad, J. Vandermeer, and D. A. Wardle. 2005. Effects of biodiversity on ecosystem functioning: a consensus of current knowledge. Ecological Monographs 75(1):3-35.

Kasperson, J. X., and R. E. Kasperson, editors. 2001. Global environmental risk. United Nations University Press, Tokyo, Japan, and Earthscan, London, UK.

Kelso, J. A. S. 1995. Dynamic patterns: the selforganization of brain and behavior. MIT Press, Cambridge, Massachusetts, USA.

Kinzig, A. P., P. Ryan, M. Etienne, H. Allison, T. Elmqvist, and B. H. Walker. 2006. Resilience and regime shifts: assessing cascading effects. Ecology and Society 11(1): 20. [online] URL: http://www.e cologyandsociety.org/vol11/iss1/art20/.

Klemens, M. W., editor. 2000. Turtle conservation. Smithsonian Institution Press, Washington, D.C., USA.

Leuteritz, T. E. J. 2002. Distribution, status, and reproductive biology of the radiated tortoise Geochelone radiata (Shaw, 1802) in southwest Madagascar. Dissertation. George Mason University, Fairfax, Virginia, USA.

Leuteritz, T. E. J. 2006. Tortoises on the march: modeling and GIS relocate a threatened species. GeoWorld 19(5):20-22.

Leuteritz, T. E. J., and M. D. Hofmeyr. 2007. The extended reproductive season of tent tortoises (Psammobates tentorius tentorius): a response to an arid and unpredictable environment. Journal of Arid Environments 68(4):546-563.

Leuteritz, T. E. J., T. Lamb, and J. C. Limberaza. 2005. Distribution, status, and conservation of radiated tortoises (Geochelone radiata) in Madagascar. Biological Conservation 124(4):451-461.

Leuteritz, T. E. J., and R. Ravolanaivo. 2005. Reproductive ecology and egg production of the radiated tortoise (Geochelone radiata) in southern Madagascar. African Zoology 40(2):233-242.

Levell, J. P. 1995. A field guide to reptiles and the 
law. Serpent's Tale Natural History Books, Excelsior, Minnesota, USA.

Levin, S. A. 1998. Ecosystems and the biosphere as complex adaptive systems. Ecosystems $\mathbf{1}$ (5):431-436.

Lingard, M., N. Raharison, E. Rabakonandrianina, J.-A. Rakotoarisoa, and T. Elmqvist. 2003. The role of local taboos in conservation and management of species: the radiated tortoise in southern Madagascar. Conservation and Society 1 (2):223-246.

McCann, K. S. 2000. The diversity-stability debate. Nature 405:228-233.

Michener, J. A. 1980. The covenant. Random House, New York, New York, USA.

Midgley, G. F., M. C. Rutherford, and W. J. Bond. 2001. The heat is on: impacts of climate change on plant diversity in South Africa. National Botanical Institute, Cape Town, South Africa.

Myers, N., R. A. Mittermeier, C. G. Mittermeier, G. A. B. da Fonseca, and J. Kent. 2000. Biodiversity hotspots for conservation priorities. Nature 403:853-858.

Nabhan, G. P. 2002. When desert tortoises talk, Indians listen. Pages 355-375 in T. R. Van Devender, editor. The Sonoran desert tortoise: natural history, biology, and conservation. University of Arizona Press, Tucson, Arizona, USA.

Norton, B. G. 1992. A new paradigm for environmental management. Pages 23-41 in R. Costanza, B. G. Norton, and B. D. Haskell, editors. Ecosystem health: new goals for environmental management. Island Press, Washington, D.C., USA.

Nussbaum, R. A., and C. J. Raxworthy. 2000. Commentary on conservation of "Sokatra," the radiated tortoise (Geochelone radiata) of Madagascar. Amphibian and Reptile Conservation 2(1):6-14.

Pimm, S. L. 1984. The complexity and stability of ecosystems. Nature 307:321-326.

Schaffer, W. M. 1984. Stretching and folding in lynx fur returns: evidence for a strange attractor in nature? American Naturalist 124(6):798-820.

Smith, S. D., T. E. Huxman, S. F. Zitzer, T. N. Charlet, D. C. Housman, J. S. Coleman, L. K. Fenstermaker, J. R. Seemann, and R. S. Nowak. 2000. Elevated $\mathrm{CO}_{2}$ increases productivity and invasive species success in an arid ecosystem. Nature 408:79-82.

Thomas, C. D., A. Cameron, R. E. Green, M. Bakkenes, L. J. Beaumont, Y. C. Collingham, B. F. N. Erasmus, M. F. de Siqueira, A. Grainger, L. Hannah, L. Hughes, B. Huntley, A. S. van Jaarsveld, G. F. Midgley, L. Miles, M. A. OrtegaHuerta, A. T. Peterson, O. L. Phillips, and S. E. Williams. 2004. Extinction risk from climate change. Nature 427:145-148.

Tilman, D. 2000. Causes, consequences and ethics of biodiversity. Nature 405:208-211.

Tracy, C. R., R. Averill-Murray, W. I. Boarman, D. Delehanty, J. Heaton, E. McCoy, D. Morafka, K. Nussear, B. Hagerty, and P. Medica. 2004. Desert tortoise recovery plan assessment. Unpublished report to the U.S. Fish and Wildlife Service, Portland, Oregon, USA. Available online at: http://www.fws.gov/nevada/desert tortoise/documents/ dtrpac/dtrpac report.pdf.

Walker, B., C. S. Holling, S. R. Carpenter, and A. Kinzig. 2004. Resilience, adaptability, and transformability in social-ecological systems. Ecology and Society 9(2): 5. [online] URL: http://w ww.ecologyandsociety.org/vol9/iss2/art5.

Webster, D. 1997. The looting and smuggling and fencing and hoarding of impossibly precious, feathered and scaly wild things. New York Times Magazine February 16:26-61. Available online at: http://query.nytimes.com/gst/fullpage.html? res=9D02E1D91F3CF935A25751C0A961958260

Whitford, W. G. 2002. Ecology of desert systems. Academic Press, London, UK. 